\title{
Variety and Incidence of Cutaneous Adverse Drug Reactions in a UAE Hospital
}

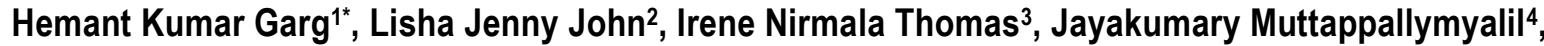 \\ Wesam Kadhum ${ }^{5}$, Jayadevan Sreedharan ${ }^{6}$ \\ ${ }^{1 *}$ Professor, ${ }^{2}$ Lecturer, Department of Pharmacology, 4Professor, Department of Community medicine, \\ ${ }^{6}$ Professor, Statistical support facility, CABRI, Gulf Medical University, Ajman, UAE. \\ ${ }^{3}$ Clinical Professor, ${ }^{5}$ Clinical Assistant Professor, \\ Department of Dermatology, Gulf Medical College Hospital, Ajman, UAE.
}

\section{ABSTRACT}

Objective: To study the clinical patterns of cutaneous adverse drug reactions (ADRs) and to identify the causative drugs.

Materials \& Methods: A cross-sectional hospital based study was carried out in patients with cutaneous ADRs reporting to the Department of Dermatology at GMC Hospital, Ajman, U. A. E., between $2010 \& 2012$. Medical records of the patients were used to obtain demographic, diagnostic and ADR related information. The data were subjected to detailed statistical analysis using SPSS.19 software.

Results: A total of 43 patients were included $(46.5 \%$ males and $53.5 \%$ female) in the study. Mean age of patients was $30.07 \pm 13.63$ years. Majority of the patients were from Middle East followed by Asian countries. The commonest cutaneous ADRs seen were maculo - papular rash (48.8\%), Erythroderma $(18.6 \%)$, urticaria $(11.7 \%)$ and Fixed drug eruption (11.7\%). The most responsible drugs for the various cutaneous ADR were antimicrobials in $11(48.8 \%)$ and NSAIDs in 14 (32.5\%) cases. Carbamazepine and Ciprofloxacin were responsible for two cases $(6 \%)$ of life-threatening Stevens Johnson syndrome. Mean reaction duration was $5.63 \pm 0.5$ days. Reactions were mild $(46.7 \%)$, moderate $(40 \%)$ and severe $(13.3 \%)$. Based on the WHO-Causality assessment of ADRs, $34(80 \%)$ cases

\section{INTRODUCTION}

Adverse drug reaction (ADR) as defined by The World Health Organization (WHO) is 'a reaction which is noxious and unintended and which occurs at doses normally used in humans for prevention, diagnosis or therapy of disease, or for the modification of physiological functions'1. Adverse drug reactions (ADRs) are important public health problem and one of the leading causes of morbidity 2 . It has been shown that approximately $5.3 \%$ of hospital admissions are associated with ADRs ${ }^{3}$. ADRs have a considerable impact on public health by imposing a heavy economic burden on the society and health-care systems ${ }^{4}$.

A wide variety of commonly prescribed drugs have been implicated in cutaneous adverse drug reactions. Cutaneous ADRs have resulted in disabling infirmities during hospitalisation and complications following out - door drug therapy. Cutaneous ADRs can present across a wide spectrum, varying from a mild maculo- were probable; $8(27 \%)$ possible and $1(3 \%)$ case uncertain in nature. A total of $5(11.6 \%)$ cases had past history of ADRs. Three patients $(9 \%)$ had secondary, bacterial infection of skin over ADR lesions and required antimicrobial treatment.

Conclusion: The clinical pattern of ADRs and the drugs causing cutaneous ADRs was largely similar to that observed in other countries, except for minor variations.

Keywords: Antimicrobials, Cutaneous adverse drug reactions, Maculo-papular rash, NSAIDs.

\section{*Correspondence to:}

Prof. Hemant Kumar Garg,

Department of Pharmacology, Gulf Medical University, Ajman, UAE.

Article History:

Received: 22-07-2016, Revised: 02-08-2016, Accepted: 14-08-2016

\begin{tabular}{|l|c|}
\hline \multicolumn{2}{|c|}{ Access this article online } \\
\hline Website: & Quick Response code \\
www.ijmrp.com & \\
\hline DOI: & \\
10.21276/ijmrp.2016.2.5.009 & \\
\hline
\end{tabular}

papular rash to toxic epidermal necrolysis (TEN) and life threatening Stevens-Johnson syndrome (SJS) etc ${ }^{5}$. Even though majority of cutaneous reactions are of benign nature, reports have documented that serious cutaneous ADRs, such as SJS/TEN are associated with significant morbidity and mortality ${ }^{6}$. The pattern of cutaneous ADRs and the drugs responsible for them change every year with the introduction of newer drugs and evolving prescription practices.

Skin Adverse drug reactions can vary in pattern in different regions. In a study by Al-Raaie $\mathrm{F}$ et al from Oman, $8.5 \%$ of the hospitalized patients experienced cutaneous ADRs ${ }^{7}$. The clinical profile observed in their study included Urticaria, Fixed Drug Eruptions (FDE) and Maculo papular Eruptions (MPE). AlGhanem $\mathrm{F}$ et al from Kuwait and Rahmati - Roodsari $\mathrm{M}$ et al from Iran reported exanthematous skin eruptions, urticarial reactions 
and FDE as the most common cutaneous $\mathrm{ADR}^{8,9}$. Rahmati Roodsari $M$ et al from Iran reported a lower prevalence of cutaneous ADRs in comparison to the reported figure in literature ${ }^{9}$. Studies on the epidemiology of cutaneous, clinical presentation and outcome of cutaneous ADRs have rarely been carried out in United Arab Emirates. This study evaluated the clinical profile of all cutaneous ADRs over a two years period in patients attending the Out Patient Department of Dermatology of Gulf Medical College Hospital, Ajman and also aimed at identifying the suspected drug, using the WHO causality definitions.

\section{DEFINITIONS}

Adverse Drug Reactions: Any unintended effect of a drug occurring at normal doses used in humans for prophylactic management, diagnosis or treatment 1

'Certain' ADR: An undesirable clinical event with a plausible time relationship to drug administration which cannot be explained by concurrent disease or other medications and responds to dechallenge. ${ }^{10}$ The event must be definitive of the drug using a rechallenge procedure if necessary.

'Probable' ADR: An undesirable clinical event with a reasonable time relationship to administration of the drug, not explained by concurrent disease or other medications and responds to dechallenge.

'Possible' ADR: An undesirable clinical event with a reasonable time relationship to administration of the drug, but which can be explained by concurrent disease or other medications. Information on the dechallenge may be lacking.

'Unlikely' ADR: An undesirable clinical event with a improbable time relationship to administration of the drug, and in which other medications or underlying disease provide plausible explanations ${ }^{10}$.

Serious adverse event: The American Food and Drug Administration defines a serious adverse event as one when the patient outcome is one of the following ${ }^{11}$ :

- Death

- Life-threatening

- Hospitalization (initial or prolonged)

- Disability - significant, persistent, or permanent change, impairment, damage or disruption in the patient's body function/structure, physical activities or quality of life.

- Congenital anomaly

- Requires intervention to prevent permanent impairment or damage

Severe drug event: Severity is a point on an arbitrary scale of intensity of the adverse event in question.

\section{MATERIALS \& METHODS}

A cross sectional, hospital based, prospective study design has been adopted in this research involving the patients reporting at Gulf Medical College Hospital and Research Centre (GMCH\&RC) with cutaneous ADRs caused by drugs prescribed by GMC doctors or by doctors other than GMCH doctors or by self medication. The study was being carried out among all patients irrespective of the gender and age attending the Outpatient department of Dermatology and also in hospitalized patients in all the wards of Gulf Medical College Hospital, Ajman, UAE w.e.f. from January 2010 to December 2011 have been included in the study. A questionnaire was used to record the relevant data of patients with cutaneous ADRs. The questionnaire included demographic characteristics, clinical diagnosis, associated comorbid conditions and relevant ADR details such as type of ADR, drug history, the suspected drug, reaction time, dechallenge history, past history of similar condition, severity, history of drug allergy or atopy, management and outcome of the ADR. The ethics committee of Gulf Medical University approved this study. Permission was also obtained from the Medical Records Department to access case records of both the OPD patients of Dermatology department and inpatients of all the wards with cutaneous ADRs. Anonymity was maintained by not recording any information revealing the identity of the patient.

\section{RESULTS}

A total of 43 patients reported to the Department of Dermatology during the study period with cutaneous ADRs. Male patients constituted $46.5 \%$ and female $53.5 \%$. The maximum number of reactions was seen in patients in the age group of 20-39 years. Mean age of patients was $30.07 \pm 13.63$ years. Majority of the patients were from Middle East [19(44\%)] followed by Asian countries [16(37.2\%)]. The details of the age and gender - wise distribution of the patients with cutaneous ADR are shown in table1. The commonest cutaneous ADRs seen were maculo papular rash [21(48.8\%)], Erythroderma [8(18.6\%)], urticaria [5(11.7\%)] and Fixed drug eruption [5(11.7\%)]. Details of the clinical spectrum of cutaneous ADRs with the implicated drugs are presented in Table 2.

The drugs responsible for most of the cutaneous ADR were antimicrobials $[21(48.8 \%)$ cases] and Non-steroidal antiinflammatory drugs (NSAIDs)[14 (32.5\%) cases]. Alternative medicine (Ivy leaves) was implicated in two cases of Maculo papular rash. Carbamazepine and Ciprofloxacin were responsible for two cases of life-threatening Stevens Johnson syndrome. The detailed list of the cutaneous ADR and the causative drugs are depicted in table 3.

Table1: Age and gender wise distribution of the patients with cutaneous ADRs

\begin{tabular}{|c|c|c|c|c|c|c|}
\hline \multirow[t]{2}{*}{ Age group } & \multicolumn{4}{|c|}{ No. Of Patients } & \multirow[t]{2}{*}{ Total } & \multirow[t]{2}{*}{$\%$} \\
\hline & Male & $\%$ & Female & $\%$ & & \\
\hline $0-19$ & 7 & 35 & 6 & 26 & 13 & 30.2 \\
\hline $20-39$ & 9 & 45 & 13 & 56.5 & 22 & 51.1 \\
\hline$>1=40$ & 4 & 20 & 4 & 17.5 & 8 & 18.6 \\
\hline Total & 20 & 100 & 23 & 100 & 43 & 100 \\
\hline
\end{tabular}


Table.2 Description of the cutaneous ADRs reported

\begin{tabular}{lcc}
\hline Cutaneous ADR & No. $(\mathbf{n}=\mathbf{4 3})$ & $\%$ \\
\hline Maculo - papular rash & 21 & 48.8 \\
Erythroderma & 8 & 18.6 \\
Urticaria & 5 & 11.7 \\
Fixed drug eruption & 5 & 11.7 \\
Steven Johnson Syndrome & 2 & 4.6 \\
Exfoliative dermatitis & 1 & 2.3 \\
Toxic Epidermonecrolysis & 1 & 2.3 \\
\hline
\end{tabular}

Table 3: Cutaneous ADRs and the implicated drugs

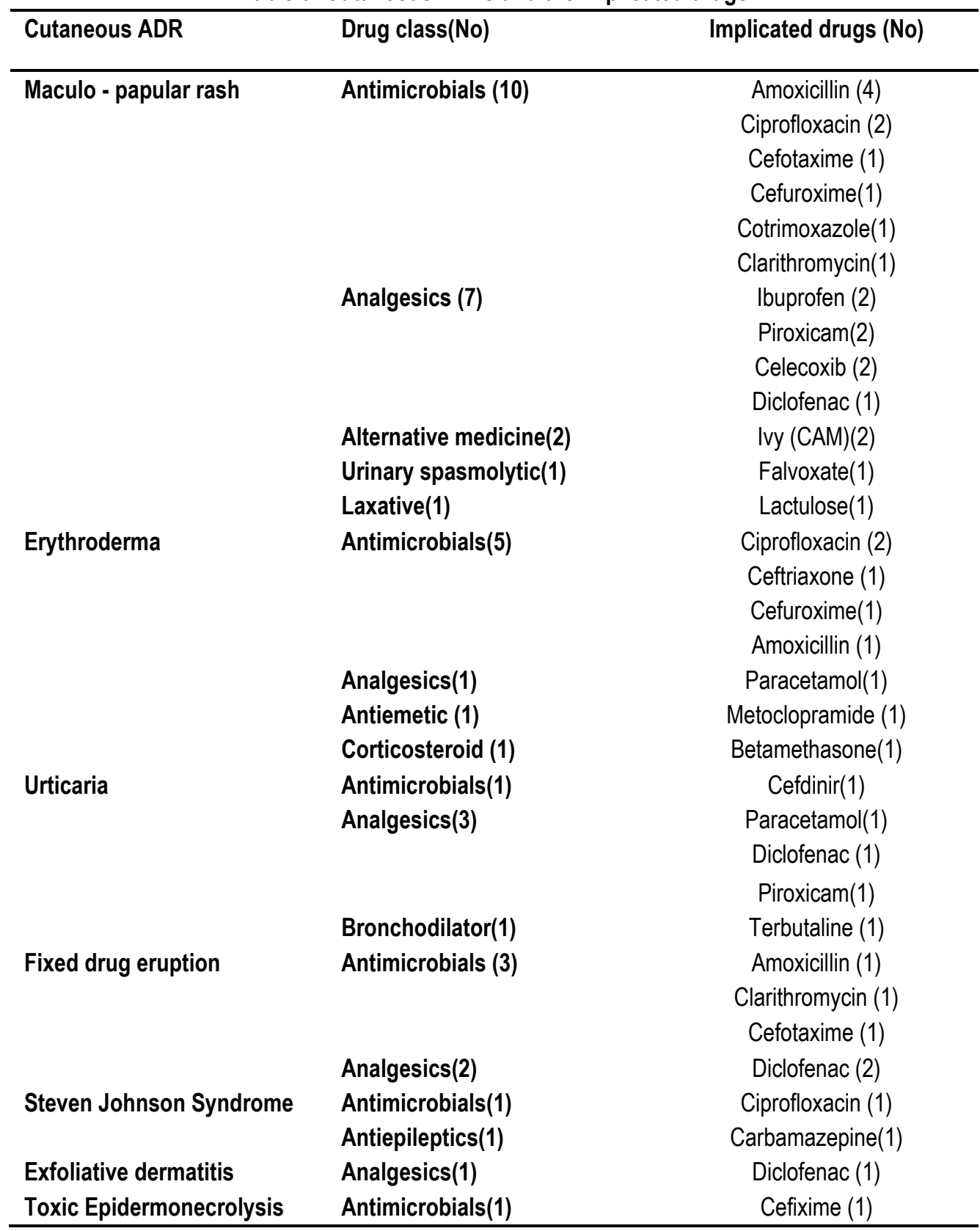

Reaction time (RT), which is the time taken for the adverse drug reaction to appear since the last exposure to the suspected drug, varied from 1 day to 45 days. Mean reaction time was $5.63 \pm 0.5$ days. Based on the severity of the ADRs, $46.7 \%$ were mild, $40 \%$ moderate and 3.3\%were severe cutaneous reactions.

Based on the WHO-Causality assessment of ADRs, 34(80\%) cases were probable in nature; $8(27 \%)$ possible and $1(3 \%)$ case was uncertain. Five (11.6\%) patients had past history of ADRs.
Two patients had history of atopy. Three patients had secondary bacterial infection over the ADR lesions and required antimicrobial treatment. No mortality occurred due to cutaneous reactions.

\section{DISCUSSION}

Diagnosis of cutaneous ADR is one of the most challenging clinical problems for the physician. Under-diagnosis and wrong prescription may expose the patient to serious and life-threatening 
iatrogenic adverse drug reactions. The results of the present study highlight the clinical pattern and implicating agents of the cutaneous ADRs reporting to GMC hospital over a period of two years.

We found a slightly higher occurrence rate of ADRs among females, which is in concordance to earlier studies across the world including the Eastern Mediterranean region,12-14. Female patients have been reported to have a 1.5 to 1.7 fold greater risk of developing an $A D R$, including skin adverse skin reactions, compared the male counterparts. The reasons for this increased risk are not entirely clear but gender-related differences in pharmacokinetic, immunological and hormonal profiles and differences in the medications used by both sexes are likely to be responsible ${ }^{3}$. Majority of the patients with cutaneous ADRs were young, of the age group 20-39 years, similar to reports of Jelvehgari et al and Solensky $R$ et al ${ }^{15,17}$. The probable reason for this observation could be an increased exposure to antimicrobials in this age group which increases the risk of drug eruptions ${ }^{16}$. In contradiction, elderly and adult aged patients were the most affected according to Al-Raaie $\mathrm{F}$ et al. from Oman? ${ }^{7}$. The difference in various studies may be related to the regional variation in the health care seeking behaviour and drug compliance of the population.

There is no gold standard investigation for confirming a druginduced reaction. The causality assessment includes analysis of a constellation of features such as timing of drug exposure and reaction time, course of reaction with drug withdrawal, recurrence on rechallenge, history of similar reaction to the suspected drug ${ }^{17}$ etc.In this study, WHO causality definitions were used to categorize the ADRs into certain, probable, possible and unlikely categories, being a very simple and widely accepted method to assess causality ${ }^{12}$. In the present study, 34(80\%) cases were probable in nature; $8(27 \%)$ possible and $1(3 \%)$ was uncertain. The reaction time observed for all the reactions in the present study was in accordance withearlierreports ${ }^{13}$.

A wide clinical spectrum of cutaneous ADRs was noticed in this study. The most common cutaneous ADRs observed in this study were maculo-papular rashes (48.8\%), followed by erythroderma $(18.6 \%)$, and urticaria (11.7\%). Our findings were similar to those reported in studies from Iran $^{9,13}$, butdiffered from reports from Oman and Kuwait, where in, the most common morphologic patterns were Urticaria followed by $\mathrm{FDE}^{7,18}$. This variation could be due to differences in patterns of drug usage and ethnic group characteristics. Occurrence rate of SJS and TEN was lower than in earlier studies ${ }^{5,13}$. In agreement with other studies from the middle east and across the world, cutaneous ADRs were most frequently caused by antimicrobial agents and NSAIDS $7,9,14,19$.

Occurrence of ADRs is influenced by several host factors. Patients with previous history of a drug reaction are more likely to develop reactions from other drugs. In the present study, $11 \%$ of the patients gave history of previous drug reaction, while Al-Raaie $F$ et al reported the percentage being $18 \%{ }^{7}$. Atopy background was present in $40 \%$ of cases of urticarial rashes which could be considered as a predisposing factor for the reactions. Other studies also have emphasized the role of atopy in drug allergy $\mathrm{y}^{7,20}$. Dechallenge of the offending drug was done in all the cases immediately after identification of the ADR and the patients were treated appropriately. Severe cases were effectively managed and closely monitored till discharge.

\section{CONCLUSION}

To conclude, the occurrence of cutaneous ADRs in the present study was similar in many ways to various other studies from the Middle East region. A wide clinical spectrum of cutaneous ADRs ranging from mild maculo-papular rash to serious SJS and TEN was observed. Antimicrobials were implicated in the majority of the cutaneous ADRs in patients. Physicians and dermatologists should use these drugs sparingly and report every drug reaction to the drug controller and WHO to generate valuable data about drug safety for health care deliverers and their beneficiaries in the country.

\section{REFERENCES}

1. WHO: Safety Monitoring of Medicinal Products: Guidelines for Setting Up and Running a Pharmacovigilance Centre. Available at http://www.who.int/medicinedocs (Accessed June 1, 2013)

2. Lazarou J, Pomeranz BH, Corey PN: Incidence of adverse drug reactions in hospitalized patients: a meta-analysis of prospective studies. JAMA 1998; 279:1200-1205.

3. Kongkaew C, Noyce PR, Ashcroft DM: Hospital admissions associated with adverse drug reactions: a systematic review of prospective observational studies. Ann Pharmacother 2008, 42:1017-1025.

4. Wu WK, Pantaleo N: Evaluation of outpatient adverse drug reactions leading to hospitalization. Am J Health Syst Pharm 2003, 60:253-259.

5. Noel MV, Sushma M, Guido S. Cutaneous adverse drug reactions in hospitalized patients in a tertiary care center. Indian J Pharmacol 2004; 36 (5):292-295.

6. Roujeau JC, Stern RS. Severe adverse cutaneous reactions to drugs. N Eng J Med 1994; 331:1272-85.

7. Al-Raaie F, Banodkar DD. Epidemiological Study of Cutaneous Adverse Drug Reactions in Oman. Oman Medical Journal 2008;23:21-27.

8. Al-Ghanem F, Al-Mutairi N. Spectrum of Cutaneous Adverse Drug Reactions seen in the Emergency Department (ED): A Prospective Study from Kuwait. Middle East Journal of Emergency Medicine 2006;6 (2): 15.

9. Rahmati-Roodsari M, Shadnia S, Abdollahi M Drug-induced skin events in hospitalized patients in Tehran, Iran: a 6-year case series study. Arch Med Sci 2009; 5(1): 91-96.

10. The use of the WHO-UMC system for standardized case causality assessment. Accessed from: http://www.WHOUMC.org/graphics/4409.pdf [last accessed on 2014 Feb 12]

11. FDA MedWatch - What Is A Serious Adverse Event? [Last accessed on 2014 Feb 12]. Available at: http://web.archive.org/web/20070929095423/http:/fda.gov/medwat ch/report/desk/advevnt.htm

12. Edwards IR, Aronson JK. Adverse drug reactions: Definitions, diagnosis and management. Lancet 2000;356:1255-1259.

13. Jelvehgari M, Azimi H, Montazam H. Prevalence of Cutaneous Drug Eruption in Hospitalized Patients: A Report from Sina Hospital of Tabriz. Iran J Dermatol 2009;12: 16-19.

14. Hernandez-Salazar A, Rosales S, Rangel-Frausto S, Criollo E, Archer-Dubon C, Orozco-Topetea R. Epidemiology of adverse cutaneous drug reactions: a prospective study in hospitalized patients. Arch Med Res 2006; 37: 899-902.

15.Rademaker M.Do women have more adverse drug reactions? Am J Clin Dermatol. 2001;2(6):349-51. 
16.Solensky R, Mendelson LM. Systemic reactions to antibiotics. Immunol Allergy Clin North Am2001; 21:679-697.

17. Shear NH, Knowles SR, Sullivan JR, Shapiro L. Cutaneous reactions to drugs. In: Freedberg IM, Eisen AZ, Wolff K, editors. Fitzpatrick's dermatology in general medicine. 6th Ed. USA: McGraw Hill, Medical publishing division; 2003. p. 1330-6.

18. Faisal Al-Ghanem, N. Al-Mutairi, Spectrum of Cutaneous Adverse Drug Reactions in the Emergency Department of AlFarwaniya Hospital. The Middle East Journal of Emergency Medicine; Kuwait, Sept 2006.

19. Capuano A, Motola G, Russo F, et al. Adverse drug events in two emergency departments in Naples, Italy: an observational study. Pharmacol Res 2004; 50: 631-6.

20. Pastorello EA, Zara C, Riario-Sforza GG, Pravettoni V, Incorvaia $\mathrm{C}$. Atopy and intolerance of antimicrobial drugs increase the risk of reactions to acetaminophen and nimesulide in patients allergic to nonsteroidal anti-inflammatory drugs. European Journal of Allergy \& Clinical Immunology 1998;53(9):880-884. doi: 10.1111/j.1398-9995.1998.tb03995.

\section{Source of Support: Nil.}

Conflict of Interest: None Declared.

Copyright: (c) the author(s) and publisher. IJMRP is an official publication of Ibn Sina Academy of Medieval Medicine \& Sciences, registered in 2001 under Indian Trusts Act, 1882.

This is an open access article distributed under the terms of the Creative Commons Attribution Non-commercial License, which permits unrestricted non-commercial use, distribution, and reproduction in any medium, provided the original work is properly cited.

Cite this article as: Hemant Kumar Garg, Lisha Jenny John, Irene Nirmala Thomas, Jayakumary Muttappallymyalil, Wesam Kadhum, Jayadevan Sreedharan. Variety and Incidence of Cutaneous Adverse Drug Reactions in a UAE Hospital. Int J Med Res Prof. 2016; 2(5):45-49. 